\title{
Recent Advances of Air Pollution Studies in Italy
}

\author{
Antonio Donateo $^{1, *(\mathbb{C}}$, Maria Gabriella Villani ${ }^{2}$, Teresa Lo Feudo ${ }^{3}(\mathbb{B})$ and Elena Chianese ${ }^{4}(\mathbb{D})$ \\ 1 Institute of Atmospheric Sciences and Climate, ISAC-CNR, 73100 Lecce, Italy \\ 2 ENEA, Italian National Agency for New Technologies, Energy and Sustainable Economic Development, \\ 21017 Ispra, Italy; mariagabriella.villani@enea.it \\ 3 Institute of Atmospheric Sciences and Climate, ISAC-CNR, 88046 Lamezia Terme, Italy; t.lofeudo@isac.cnr.it \\ 4 Department of Science and Technology, Parthenope University of Naples, 80143 Napoli, Italy; \\ elena.chianese@uniparthenope.it \\ * Correspondence: a.donateo@isac.cnr.it; Tel.: +39-0832-422-417
}

Received: 25 September 2020; Accepted: 29 September 2020; Published: 1 October 2020

This special issue collects 18 original and review articles dealing with different recent advances in air pollution studies in Italy, from urban to rural environments, from model to experimental approaches. Despite continuous improvements in recent decades, air pollution in Italy still represents a great concern according to normative thresholds for main pollutant concentrations (in particular $\mathrm{PM}_{2.5}, \mathrm{PM}_{10}$, $\mathrm{O}_{3}, \mathrm{NO}_{2}, \mathrm{PAHs}, \mathrm{NO}$ ), both in cities and in rural areas. In recognition of the Italian framework, this special issue aimed to showcase some of the most recent findings related to air quality investigations in our country.

In fact, according to European Environmental Agency (EPA) reports and World Health Organization (WHO) studies, the Po Valley region and a number of Italian cities have sadly become well known for being the worst in Europe in terms of air pollution, constituting an economic and societal challenge for policymakers. The Po Valley (Northern Italy), a densely populated and heavily industrialized area, represents an important exceedance zone of the air-quality limit values for $\mathrm{PM}, \mathrm{NO}_{2}$ and $\mathrm{O}_{3}$. So, it is important to consider the effects of emission reduction policies and air quality control strategies. In particular, in the study presented by Raffaelli et al. [1], future emission scenarios consider the emissions reduction due to the air-quality action plans of the regions involved. The combination of a series of public measures will lead to the reduction of direct emissions of $\mathrm{PM}_{10}$ in the Po Valley and of the main precursors emitted in the area (nitrogen oxides and ammonia). Italy is characterized by a very variable configuration in terms of altitude, proximity to the sea, latitude, and the presence of industrial plants. Cristofanelli et al. [2] investigated the behaviour of methyl chloride $\left(\mathrm{CH}_{3} \mathrm{Cl}\right)$ in the Po Basin at the Mt. Cimone (GAW global station). $\mathrm{CH}_{3} \mathrm{Cl}$ is a chlorine-containing trace gas in the atmosphere contributing significantly to stratospheric ozone depletion. While the atmospheric $\mathrm{CH}_{3} \mathrm{Cl}$ emissions are predominantly caused by natural sources on the global budget, significant uncertainties still remain for the anthropogenic $\mathrm{CH}_{3} \mathrm{Cl}$ emission. This study suggested that, even if the role of natural marine emissions appears as predominant, the northern Italy boundary layer with its anthropogenic emissions could potentially represent a non-negligible source of $\mathrm{CH}_{3} \mathrm{Cl}$.

Two works have been presented in this special issue about the city of Taranto, one of the most industrialized towns in southern Italy due to the presence of the biggest European steel plant. Lucarelli et al. [3], in the framework of an extensive environmental investigation, collected aerosol samples at high time resolution, analysing them by the advanced technique of PIXE. In this study, the high time resolution of the adopted approach allowed to follow in detail the changes in the aerosol elemental composition due to both the time evolution of the industrial emissions and the changes in meteorological conditions. Di Gilio et al. [4], in the city of Taranto, took into consideration the total particle-bound Polycyclic Aromatic Hydrocarbons (p-PAHs). They found that p-PAHs concentration did not decrease with distance from the steel plant and higher concentrations were registered also in 
the urban settlement. They identified vehicular traffic as an important source of p-PAHs and highlighted the possible high short-term effect that vehicular traffic sources could have on the health of the exposed human population. Novel research studies that investigate air quality in urban environment were presented in three papers. In the first paper, Rizza et al. [5] investigated, using the MERRA-2 reanalysis, urban air pollution at a national scale by analysing the AOD (Aerosol Optical Depth) for 30-year period (1987-2017) over five Italian cities (Milan, Rome, Cagliari, Taranto, and Palermo). AOD evolution predicted by the MERRA-2 model in the period 2002-2017 showed a generalized decreasing trend over the selected cities. In the second paper, Perrino et al. [6] summarized the chemical characterization of $\mathrm{PM}_{10}$ obtained from 38 sampling campaigns carried out in 16 sites in Italy during the years 2008-2018. Chemical determinations include all macro-components (six macro-elements, eight ions, elemental carbon, and organic carbon). The chemical composition of the atmospheric aerosol clearly reflects the variety in the Italian territory and the pronounced seasonal variations in the meteo climatic conditions that characterize the country. Also in the third paper, Nava et al. [7] presented an extensive field campaign carried out in Florence (Tuscany) to investigate the $\mathrm{PM}_{2.5}$ chemical composition and to identify its sources. The scientific objective of this study is providing a reliable source apportionment in order to organize effective mitigation actions.

Because of the great concern represented by the influence of vehicular traffic on air quality, many studies have been devoted to this topic. Rossi et al. [8] made use of the Dial approach to monitor the pollution in a very congested urban area with high traffic. Indeed, the combination of Lidar and Dial techniques can be used to provide detailed information about the presence of aerosols and pollutants. Additionally, Fumian et al. [9] reported about an active remote sensing detection technology, in order to monitor dispersion in the environment of volatile chemical substances. In this study, a new system architecture derived from the integration of a low-cost laser-based network detector for pollutants interfaced with a more sophisticated layout mounted on an unmanned aerial vehicle (UAV). Zooming in our cities, this special issue presents air quality investigations relating to indoor (in a bakery) environment investigation [10], as well as the relationship between outdoor and indoor pollution concentration [11].

In relation to air pollution caused by municipal solid waste incinerators plants, Conca et al. [12] investigated the evolution of the inorganic composition of $\mathrm{PM}_{10}$ samples collected in the vicinity of the Turin incinerator before and after its commissioning. The purpose was to identify the PM sources present in the area and to evaluate if the operation of the incinerator caused an increase of the concentration of specific chemical species. They found an increment in pollutant concentration, which was may had been not directly caused by the plant emissions. The most probable source of these elements is the highway vehicular traffic, which might have increased due to the travelling of trucks carrying waste to the incinerator. Roveda et al. [13] presented a work about the emission volatile organic compounds (VOCs) by refinery plants. Based on the study of the scientific and technical literature regarding the Italian and European refining scenarios, an attempt was made to verify the existence of a correlation between the size of a refinery and the related total VOC emissions. Once this correlation was evaluated, it was possible to develop an emission factor for VOC emissions considering the plant capacity as the related activity index. Odour pollution is nowadays recognized as a serious environmental concern. Italy still lacks a national regulation about odours, even of several regions issued specific guidelines, which combine smell measurements with dispersion modelling for assessing odour impacts. Bax et al. [14] describes the monitoring by a commercial electronic nose of odours from an area dedicated to tire storage, a diffuse source with variable emissions over time, for which dispersion modelling is not applicable. Local and regional sources of emissions generally cause most of air pollution problems.

However, air pollution does not stop at national borders, thus causing transboundary flows of pollutants occurring between neighbouring countries up to the continental scale. In this context, the Italian territory is often subjected to Saharan dust transport from North Africa. Calidonna et al. [15] focused on Sahara dust storms approaching South Italy. They studied how air masses come from North 
Africa and showed a detailed study integrating many approaches, in particular surface and column optical properties, chemical properties, large scale pattern circulation, air-quality modelling/satellite products, and back-trajectory analysis

Due to the fact that critical air pollutant concentration levels primarily have consequences for human health, in terms of health care costs, morbidity and premature deaths, studies on health effects were also considered. Romano et al. [16] considered different analytical techniques to investigate the relationships between oxidative potential and metal, $\mathrm{Br}, \mathrm{P}, \mathrm{S}$, and Se concentration in $\mathrm{PM}_{10}$ samples. The integrated approach based on two different techniques allowed to better highlight the potentially harmful effects associated with specific metals and other chemical elements in $\mathrm{PM}_{10}$ samples.

The accurate estimation of air pollution represents a very important tool for health and air quality managers to elaborate informed short- and long-term strategies for air pollutions control and mitigation measures to reduce exposure risks. This special issue presents two "state of the art" studies relating to air quality forecasting over Italy. Adani et al. [17] present the operational high-resolution air quality forecasting system FORAIR_IT, developed and maintained by the Italian National Agency for New Technologies, Energy and Sustainable Economic Development, able to provide 3-day forecasts of concentrations of atmospheric pollutants over Europe and Italy, on a daily basis, with high spatial resolution (20 km on Europe, $4 \mathrm{~km}$ on Italy). Stortini et al. [18] reported about an operational forecasting and daily assessment system of air quality. This new system is able to develop and implement a service for air quality forecasting and monitoring in the Italian domain, running every day on the national territory. The system forecasts and analyses air quality for the principal pollutants: particulate matter $\left(\mathrm{PM}_{10}\right)$, ozone $\left(\mathrm{O}_{3}\right)$, and nitrogen dioxide $\left(\mathrm{NO}_{2}\right)$.

The articles collected by this special issue provide significant, yet not exhaustive, insights in showing how the air pollution problem in Italy is tackled thorough monitoring and modelling techniques. As already previously mentioned, air pollution in Italy still requires efforts, which need to occur at local, regional, national, and continental scale in concert with global partners.

Author Contributions: Writing—original draft, A.D., M.G.V., T.L.F. and E.C.; Writing—review \& editing, A.D., M.G.V., T.L.F. and E.C. All authors have read and agreed to the published version of the manuscript.

Funding: This research received no external funding

Conflicts of Interest: The authors declare no conflict of interest.

\section{References}

1. Raffaelli, K.; Deserti, M.; Stortini, M.; Amorati, R.; Vasconi, M.; Giovannini, G. Improving Air Quality in the Po Valley, Italy: Some Results by the LIFE-IP-PREPAIR Project. Atmosphere 2020, 11, 429. [CrossRef]

2. Cristofanelli, P.; Arduini, I.; Calzolari, F.; Giostra, U.; Bonasoni, P.; Maione, M. First Evidences of Methyl Chloride $(\mathrm{CH} 3 \mathrm{Cl})$ Transport from the Northern Italy Boundary Layer during Summer 2017. Atmosphere 2020, 11, 238. [CrossRef]

3. Lucarelli, F.; Calzolai, G.; Chiari, M.; Giardi, F.; Czelusniak, C.; Nava, S. Hourly Elemental Composition and Source Identification by Positive Matrix Factorization (PMF) of Fine and Coarse Particulate Matter in the High Polluted Industrial Area of Taranto (Italy). Atmosphere 2020, 11, 419. [CrossRef]

4. Di Gilio, A.; Palmisani, J.; Trizio, L.; Saracino, G.; Giua, R.; de Gennaro, G. Total p-PAH Levels Nearby a Complex Industrial Area: A Tailored Monitoring Experiment to Assess the Impact of Emission Sources. Atmosphere 2020, 11, 469. [CrossRef]

5. Rizza, U.; Mancinelli, E.; Morichetti, M.; Passerini, G.; Virgili, S. Aerosol Optical Depth of the Main Aerosol Species over Italian Cities Based on the NASA/MERRA-2 Model Reanalysis. Atmosphere 2019, $10,709$. [CrossRef]

6. Perrino, C.; Catrambone, M.; Canepari, S. Chemical Composition of $\mathrm{PM}_{10}$ in 16 Urban, Industrial and Background Sites in Italy. Atmosphere 2020, 11, 479. [CrossRef]

7. Nava, S.; Calzolai, G.; Chiari, M.; Giannoni, M.; Giardi, F.; Becagli, S.; Severi, M.; Traversi, R.; Lucarelli, F. Source Apportionment of $\mathrm{PM}_{2.5}$ in Florence (Italy) by PMF Analysis of Aerosol Composition Records. Atmosphere 2020, 11, 484. [CrossRef] 
8. Rossi, R.; Di Giovanni, D.; Malizia, A.; Gaudio, P. Measurements of Vehicle Pollutants in a High-Traffic Urban Area by a Multiwavelength Dial Approach: Correlation Between Two Different Motor Vehicle Pollutants. Atmosphere 2020, 11, 383. [CrossRef]

9. Fumian, F.; Di Giovanni, D.; Martellucci, L.; Rossi, R.; Gaudio, P. Application of Miniaturized Sensors to Unmanned Aerial Systems, A New Pathway for the Survey of Polluted Areas: Preliminary Results. Atmosphere 2020, 11, 471. [CrossRef]

10. Ielpo, P.; Placentino, C.M.; Genga, A.; Ancona, V.; Uricchio, V.F.; Fermo, P. PM 2.5 in Indoor Air of a Bakery: Chemical Characterization and Size Distribution. Atmosphere 2020, 11, 415. [CrossRef]

11. Tofful, L.; Perrino, C.; Canepari, S. Comparison Study between Indoor and Outdoor Chemical Composition of $\mathrm{PM}_{2.5}$ in Two Italian Areas. Atmosphere 2020, 11, 368. [CrossRef]

12. Conca, E.; Malandrino, M.; Giacomino, A.; Inaudi, P.; Buoso, S.; Bande, S.; Sacco, M.; Abollino, O. Contribution of the Incinerator to the Inorganic Composition of the $\mathrm{PM}_{10}$ Collected in Turin. Atmosphere 2020, 11, 400. [CrossRef]

13. Roveda, L.; Polvara, E.; Invernizzi, M.; Capelli, L.; Sironi, S. Definition of an Emission Factor for VOC Emitted from Italian and European Refineries. Atmosphere 2020, 11, 564. [CrossRef]

14. Bax, C.; Sironi, S.; Capelli, L. Definition and Application of a Protocol for Electronic Nose Field Performance Testing: Example of Odor Monitoring from a Tire Storage Area. Atmosphere 2020, 11, 426. [CrossRef]

15. Calidonna, C.R.; Avolio, E.; Gullì, D.; Ammoscato, I.; De Pino, M.; Donateo, A.; Lo Feudo, T. Five Years of Dust Episodes at the Southern Italy GAW Regional Coastal Mediterranean Observatory: Multisensors and Modeling Analysis. Atmosphere 2020, 11, 456. [CrossRef]

16. Romano, S.; Becagli, S.; Lucarelli, F.; Russo, M.; Pietrogrande, M.C. Oxidative Potential Sensitivity to Metals, $\mathrm{Br}, \mathrm{P}, \mathrm{S}$, and Se in $\mathrm{PM}_{10}$ Samples: New Insights from a Monitoring Campaign in Southeastern Italy. Atmosphere 2020, 11, 367. [CrossRef]

17. Adani, M.; Piersanti, A.; Ciancarella, L.; D’Isidoro, M.; Villani, M.G.; Vitali, L. Preliminary Tests on the Sensitivity of the FORAIR_IT Air Quality Forecasting System to Different Meteorological Drivers. Atmosphere 2020, 11, 574. [CrossRef]

18. Stortini, M.; Arvani, B.; Deserti, M. Operational Forecast and Daily Assessment of the Air Quality in Italy: A Copernicus-CAMS Downstream Service. Atmosphere 2020, 11, 447. [CrossRef] 